Artigo Original - 461 -

\title{
A EFETIVAÇÃO DOS DIREITOS DOS USUÁRIOS DE SAÚDE COM DIABETES MELLITUS: CO-RESPONSABILIDADES ENTRE PODER PÚBLICO, PROFISSIONAIS DE SAÚDE E USUÁRIOS
}

\author{
Ellen Cristina Barbosa dos Santos ${ }^{1}$, Carla Regina de Souza Teixeira², Maria Lúcia Zanettỉ, Manoel Antônio \\ dos Santos ${ }^{4}$
}

\footnotetext{
${ }^{1}$ Mestre em Enfermagem. Professora do Centro Acadêmico de Vitória da Universidade Federal de Pernambuco. Pernambuco, Brasil. E-mail: ellenbarbosa@usp.br

${ }^{2}$ Doutora em Enfermagem. Professora do Departamento de Enfermagem Geral e Especializada da Escola de Enfermagem de Ribeirão Preto (EERP) da Universidade de São Paulo (USP). São Paulo, Brasil. E-mail: carlarst@eerp.usp.br

${ }^{3}$ Doutora em Enfermagem. Professora Associado do Departamento de Enfermagem Geral e Especializada da EERP/USP. São Paulo, Brasil. E-mail: zanetti@eerp.usp.br

${ }^{4}$ Doutor em Psicologia Clínica. Professor do Departamento de Psicologia e Educação da Faculdade de Filosofia, Ciências e Letras de Ribeirão Preto da USP. São Paulo, Brasil. E-mail: masantos@ffclrp.usp.br
}

\begin{abstract}
RESUMO: Estudo descritivo de abordagem qualitativa, com objetivo de analisar o conhecimento do usuário com Diabetes Mellitus acerca dos seus direitos em saúde. Participaram 12 pessoas com diabetes atendidas em um centro universitário do interior paulista em 2008, por meio de entrevista aberta. A análise de conteúdo temática possibilitou identificar três categorias: papel do poder público na divulgação de informações; competências e responsabilidades dos profissionais de saúde: dever ético-moral em informar; e participação ou isenção dos usuários na busca por informações sobre seus direitos. Foi possível constatar que, apesar dos avanços legalmente alcançados pelas políticas públicas, os usuários com diabetes desconhecem informações sobre seus direitos. Ressaltamos a necessidade de que as informações sejam compartilhadas entre: poder público, profissionais de saúde e usuários com o intuito de promover a qualidade da assistência em saúde, permeada pelo respeito aos direitos dos usuários da saúde com diabetes.
\end{abstract}

DESCRITORES Enfermagem. Diabetes mellitus. Direitos do paciente. Políticas públicas. Bioética.

\section{EXERCISING THE RIGHTS OF HEALTH CARE USERS WITH DIABETES MELLITUS: CO-RESPONSIBILITIES AMONG PUBLIC POWER, HEALTH PROFESSIONALS, AND USERS}

\begin{abstract}
The goal of this descriptive study with a qualitative approach is to analyze Brazilian Diabetes Mellitus user knowledge about their health rights. Twelve participants with diabetes were attended in 2008 at a university center in the countryside of the state of São Paulo, Brazil, by means of an open interview. Thematic content analysis made it possible to identify three categories: the role of the public power in disseminating information; health professionals' competencies and responsibilities: the moral-ethical duty to inform; and user participation or exemption in searching for information about their rights. We emphasize the need to share information among: public power, health professionals, and users with the intent of promoting the quality of health assistance, permeated with respect for the health rights of users with diabetes.

DESCRIPTORS: Nursing. Diabetes Mellitus. Patient rights. Public policies. Bioethics.

\section{EJERCICIO DEL DERECHO A LA SALUD DE LOS USUARIOS CON DIABETES MELLITUS: CORRESPONSABILIDAD ENTRE EL PODER PÚBLICO, LOS PROFESIONALES Y LOS USUARIOS}

\begin{abstract}
RESUMEN: Estudio descriptivo de enfoque cualitativo, con el fin de analizar el conocimiento del usuario con Diabetes Mellitus acerca de su derecho a la salud. Los participantes del estudio son doce personas con diabetes atendidas en un centro universitario de una ciudad del Estado de Sao Paulo, Brasil, en 2008, mediante entrevistas abiertas. El análisis del contenido temático posibilitó identificar tres categorías: el papel del poder publico en la difusión de información, competencia y responsabilidad de los profesionales de la salud: el deber ético y moral de informar y, la participación o exención de los usuarios en la búsqueda de información sobre sus derechos. Se constató que, a pesar de las mejoras hechas legalmente por las políticas publicas, los usuarios con diabetes desconocen informaciones sobre sus derechos. Hacemos hincapié en la necesidad de que las informaciones sean compartidas entre el poder público, los profesionales de la salud y los usuarios con el fin de promover la calidad de la atención, impregnada por el respecto de los derechos a la salud de los usuarios con diabetes
\end{abstract}

DESCRIPTORES: Enfermería. Diabetes Mellitus. Derechos del paciente. Políticas públicas. Bioética. 


\section{INTRODUÇÃO}

O Diabetes Mellitus (DM) é uma doença crônica cuja gravidade decorrente do mau controle metabólico leva às complicações crônicas tornando os meios para controlá-la muito onerosos, não apenas para os indivíduos afetados e suas famílias, como também, para o sistema de saúde. ${ }^{1}$

Dessa forma, há necessidade de estabelecer políticas públicas voltadas para a criação de mecanismos que minimizem tanto o aparecimento quanto o agravamento da doença, com o intuito de reduzir os custos advindos da falta de detecção precoce e das complicações agudas e crônicas relacionadas às dificuldades de controle metabólico no DM. ${ }^{2}$

Nesse sentido, em 29 de setembro de 2007, entrou em vigor a Lei Federal $n^{0} 11.347 / 06$, que dispõe sobre a distribuição gratuita de medicamentos e insumos necessários à aplicação de insulina e à monitorização da glicemia capilar aos usuários acometidos pela doença e inscritos em programas de educação em diabetes. ${ }^{3}$ Para detalhar e regulamentar a distribuição gratuita dos benefícios advindos da Lei Federal $n^{\circ} 11.347 / 06$, a Portaria $\mathrm{n}^{\mathrm{o}} 2.583 / 07$ definiu o elenco de medicamentos e insumos disponibilizados aos usuários com DM, no âmbito do Sistema Único de Saúde (SUS). ${ }^{4}$

Entretanto, para que os direitos do usuário com DM, previstos na legislação, sejam assegurados, é necessário sua divulgação de modo a torná-los conhecidos pela população e profissionais de saúde.

Dessa maneira, torna-se evidente a responsabilidade dos profissionais de saúde, como atores pró-ativos, na incorporação de uma postura reflexiva e ética, que contemple a adoção de novos conhecimentos e habilidades necessárias para a efetiva comunicação com os usuários dos serviços de saúde. O estabelecimento de uma comunicação eficaz entre os usuários e os profissionais é um dos eixos norteadores da Bioética. Nisso reside um dos principais papéis da Bioética, ${ }^{5}$ uma disciplina recente que têm ganhado destaque crescente nos últimos anos.

Tendo em vista a necessidade de redirecionamento da prática assistencial, uma linguagem discutida pela Bioética é a de que o exercício dos direitos, pelos usuários, deve visar o alcance da humanização dos serviços de saúde, além de garantir a cidadania em saúde. A Bioética propõe questões acerca da humanização e da personalização dos serviços de saúde, bem como a promoção dos direitos do paciente. Nesse contexto, o direito à saúde passa a constituir o valor maior do paradigma bioético. ${ }^{5}$

Entendendo que o conhecimento dos direitos dos usuários é essencial para o desenvolvimento de uma consciência democrática, responsável e reflexiva do cidadão, tanto no papel de usuário quanto no de profissional da saúde, conhecer os direitos é o primeiro passo para diminuir as barreiras enfrentadas pelos usuários com DM para o acesso pleno a seus direitos de cidadania. ${ }^{6}$ Nesse sentido, o presente estudo teve por objetivo compreender como os usuários de saúde com DM têm se apropriado dos benefícios e direitos em saúde garantidos pela legislação vigente, por meio de duas questões norteadoras: quais as informações que possui acerca de seus direitos como usuário de saúde com DM? Como têm utilizado seus direitos?

\section{REFERENCIAL TEÓRICO}

Para fundamentar o presente estudo utilizaram-se os princípios da Bioética Principialista ${ }^{7}$ e os documentos oficiais acerca dos direitos dos usuários com DM em saúde, que regulamenta a distribuição gratuita de medicamentos e materiais necessários à aplicação de insulina e à monitoração da glicemia capilar. ${ }^{3-4}$

O Modelo Bioético Principialista é baseado em quatro princípios fundamentais: autonomia, beneficência, não-maleficência e justiça. $O$ princípio de autonomia refere-se à capacidade que a pessoa possui em autogovernar-se, de possuir liberdade de escolha e de agir em conformidade com sua própria vontade. Já a beneficência está relacionada ao comportamento ético de fazer o bem, visando à promoção do bem-estar das pessoas. A não-maleficência diz respeito à necessidade de prevenir possíveis danos às pessoas, resumindo-se a não fazer o mal. E, por fim, o princípio da justiça implica eqüidade na distribuição de bens, benefícios e serviços prestados na saúde. ${ }^{7}$

Atualmente, as pessoas com DM dispõem, no mercado, de uma ampla variedade de medicamentos, insumos e aparelhos para o controle da sua doença. A criação de normas e rotinas creditadas e validadas por leis e portarias pode vir a configurar uma legislação ativa e eficaz, sustentada por pensamento ético vigente e que contemple a participação social e o pleno exercício da cidadania.

Entretanto, não se trata apenas de construção de normas, portarias ou leis, mas de colocar em questão a praticidade de implementação das mesmas, visando o melhor controle metabólico das 
pessoas com DM, ao propiciar a individualidade de cada ser humano e a formação de cidadãos capazes de exercer seus direitos com autonomia.

Discussões atuais, advindas da formalização dos direitos dos usuários, referenciam a Bioética como moderadora das ações de saúde e das repercussões dessas ações, conduzindo a reflexões acerca dos direitos dos usuários, acesso aos direitos e disseminação de informações relativas ao uso adequado dos mesmos nos serviços de saúde. Autores também apontam a importância na formação profissional do enfermeiro. ${ }^{5-8}$

A equidade como um princípio instrumentalizador do direito à saúde está estritamente interligado a um dos quatro princípios fundamentais da bioética citados anteriormente, ou seja, da justiça, uma vez que promove o reconhecimento de necessidades diferentes, oriundas de sujeitos também diferentes, para atingir direitos iguais. ${ }^{8}$ Constata-se que a alocação de recursos pelo SUS aos usuários com DM segue tal princípio, evidenciado, por exemplo, por meio das recomendações para a monitorização da glicemia capilar no domicílio. Nessa direção, os usuários com DM tipo 2, que utilizam para o tratamento antidiabéticos orais, realizam a monitorização da glicemia capilar na própria unidade de saúde. Já os usuários com DM tipo 1 têm o direito de receber, gratuitamente, do serviço de saúde, o glicosímetro e as tiras reagentes, necessários para a realização da glicemia capilar em domicílio. ${ }^{4}$

Nesse sentido, problematizar questões relacionadas à alocação de recursos poderá dar origem a estratégias que beneficiem a desconstrução e/ ou aperfeiçoamento de práticas vigentes, contribuindo para garantir o exercício da cidadania do usuário com DM, no âmbito da justiça distributiva. Os princípios bioéticos, também presentes no Código de Ética dos Profissionais de Enfermagem, deve permear todas as ações destes profissionais, norteando a sua prática clínica, diante de qualquer usuário $^{9}$ e, em particular, aquele com DM, que já conquistou o seu espaço com a formulação de leis específicas que legitimam e protegem seus direitos.

No entanto, a Lei Federal n ${ }^{\circ} 11.347 / 06^{3}$, que garante a distribuição gratuita de medicamentos e insumos as pessoas com diabetes mellitus encontra-se no estágio de operacionalização, o que requer estudos voltados para a praticidade e exeqüibilidade dessas leis no contexto nacional. ${ }^{3-4}$ Também é necessário avançar nas investigações que abordem, especialmente, a percepção que os usuários com DM têm sobre essas leis e suas implicações no dia a dia, e na assistência de enfermagem. Entende-se que o conhecimento que os usuários têm sobre os seus direitos e o modo como eles têm se apropriado dos benefícios assegurados pela legislação vigente podem trazer subsídios valiosos para o planejamento de estratégias de avaliação dos programas implementados.

\section{METODOLOGIA}

Trata-se de estudo descritivo de abordagem qualitativa, com objetivo de analisar o conhecimento do usuário com DM acerca dos seus direitos em saúde, realizado em um Centro de Pesquisa e Extensão Universitária, do interior paulista, em 2008. Os critérios de inclusão estabelecidos foram: usuários dos serviços de saúde com mais de 18 anos, que estavam vinculados ao Grupo de Educação em Diabetes, no período de agosto a dezembro de 2008, e que consentiram em participar do estudo. O critério para escolha dos usuários foi a disponibilidade dos usuários com DM para a realização da entrevista, caracterizando uma amostra de conveniência.

Por tratar-se de estudo com abordagem qualitativa, o critério de representatividade da amostra para o encerramento da coleta de dados não foi o numérico, mas a variabilidade que permitiu abranger a totalidade do problema investigado em suas múltiplas dimensões, ou seja, adotou-se o critério da saturação dos dados. Considera-se esgotada ou satisfatória a amostra quando se obtém respostas em profundidade para os questionamentos estabelecidos, em associação à repetição do discurso por outros entrevistados. ${ }^{10}$ Neste estudo a saturação do discurso foi alcançada com 12 entrevistas realizadas com usuários dos serviços de saúde adultos com DM em relação às questões norteadoras: quais as informações que o(a) senhor(a) possui acerca de seus direitos como usuários de saúde com DM? Como o(a) senhor(a) têm utilizado os seus direitos?

A coleta de dados foi realizada no período de setembro a dezembro de 2008. Os dados foram coletados pelo pesquisador após a participação do usuário de saúde com DM nas atividades propostas pelo Grupo de Educação em Diabetes. As entrevistas foram abertas, aplicadas individualmente, em situação face a face, em ambiente preservado e com condições adequadas de conforto, com duração média de 30 minutos.

As entrevistas foram gravadas a fim de garantir a fidedignidade do registro das respostas. Os depoimentos obtidos foram transcritos integralmente, sendo realizada uma leitura exaustiva do material 
empírico. A seguir, foram selecionadas partes do material, configurados de acordo com critérios de relevância que constituíram as unidades de significado, as quais foram codificadas e organizadas em categorias, relacionando-as aos temas. ${ }^{10} \mathrm{~A}$ análise dos temas foi fundamentada nos documentos oficiais identificados por meio do levantamento acerca dos direitos do usuário dos serviços de saúde com DM e dos princípios da Bioética.

O projeto de pesquisa foi aprovado pelo Comitê de Ética em Pesquisa da Escola de Enfermagem de Ribeirão Preto da Universidade de São Paulo, sob número de protocolo 0869/2008. Os sujeitos, após os esclarecimentos do objetivo e natureza do estudo, assinaram o Termo de Consentimento Livre e Esclarecido. Neste estudo os nomes citados nas falas dos participantes foram substituídos por nomes fictícios. Foram utilizados códigos (E1, E2...) para designar cada entrevistado, respeitando-se o princípio do anonimato.

\section{RESULTADOS E DISCUSSÃO}

\section{Caracterização dos participantes}

Dos 12 participantes da pesquisa, $50 \%$ do total é do sexo masculino e $50 \%$ do feminino. A idade variou de 42 a 74 anos de idade. Houve predomínio de sujeitos na faixa etária de 60 a 69 anos. Quanto à escolaridade e estado civil, a maioria cursou até o segundo grau completo e é casada, respectivamente. A renda familiar predominante foi de quatro salários-mínimos. No que se refere à ocupação, 50\% dos sujeitos são aposentados.

Quanto ao tipo de DM, a maioria tem o DM tipo 2 e $50 \%$ utilizam antidiabéticos orais, e 50\% faz uso de insulina ou antidiabético oral associado à insulina. Em relação à obtenção dos medicamentos, $50 \%$ deles recebe das Unidades Básicas de Saúde (UBS); o restante recebe nas UBS e/ ou nas farmácias populares.

Em relação à monitorização da glicemia capilar, verificou-se que apenas metade dos participantes realiza. Constatou-se também que a totalidade dos participantes nunca havia participado de outro programa educativo.

Tendo em vista que a informação é indispensável para o processo de construção da cidadania, emergiu o tema a co-responsabilidade em saúde no que diz respeito ao fornecimento de informações e à efetivação dos direitos dos usuários com DM. Três categorias configuram esse tema: o papel do poder público na divulgação das informações, as competências e responsabilidades dos profissionais de saúde: dever ético-moral em informar e a participação ou isenção dos usuários na busca por informações.

\section{O papel do governo na divulgação e no cumprimento das informações}

Nas sociedades modernas, estruturadas como democracias representativas, todos os direitos, de alguma forma, relacionam-se com o direito à informação. Com isso, pressupõe-se que o alargamento do direito à informação pode resultar em um alargamento no exercício da cidadania. Assim, a informação representa um pressuposto básico para o processo de construção de uma sociedade democrática. ${ }^{11}$

Diante do contexto de saúde atual, no qual a saúde é um direito de todos e dever do Estado, é possível notar através da fala a seguir que há a necessidade de divulgação da informação relacionada aos direitos dos usuários pelo governo: [...] eu acho que deveria ter uma melhor divulgação, uma divulgação precisa. Porque quem não tem conhecimento não pode ir atrás do que não conhece! Ele só vai atrás quando ele é informado [...] (E8).

O entendimento de que o acesso à informação é uma porta de acesso a outros direitos nos leva a pensar que, sendo a saúde um direito social garantido constitucionalmente, é função do Estado prover e garantir o acesso às informações relativas ao SUS, dentre essas os direitos dos usuários envolvidos no processo de saúde-doença. ${ }^{11}$

A partir da informação é possível julgar situações, assumir condutas e exercer direitos como pessoas pró-ativas, autônomas e cidadãs. A fala a seguir exemplifica a percepção que o usuário possui sobre a importância de se conhecer direitos para se posicionar de maneira autônoma: [...] quando a gente tem conhecimento dos nossos direitos a gente tem mais autonomia para reivindicar. A gente só reivindica o que a gente conhece que é de direito nosso, não é?Por isso que eu acho que todo mundo tem que ter acesso a essas informações, sobre os nossos direitos [...] (E4).

Portanto, trata-se de "viabilizar a igualdade para todos na possibilidade de desenvolverem sua autonomia ética", 12:330 fornecendo subsídios à sociedade através da disponibilização das informações em saúde, para que todos possam exercer seus direitos e não somente os mais favorecidos. Isso pode ser percebido através da fala que se segue: [...] se você não tem informação, você nem usufrui do direito e nem pode passar para o outro porque você não 
tem a informação. Ela se torna dependente de alguém que saiba, ou então não vai saber nunca. A informação é o ponto chave, depois que a pessoa tem o conhecimento, aí sim ela tem condição de optar pelo sim ou pelo não, de querer tentar conseguir o medicamento gratuito ou de querer comprar. Mas ela tem que ter o conhecimento pra optar [...] (E8).

Por autonomia, um dos princípios básicos da Bioética entende-se o autogoverno, a autodeterminação da pessoa em tomar decisões relacionadas à sua vida, à sua saúde, à sua integridade físico-psiquíca e às suas relações sociais, presumindo a existência de opções, liberdade de escolha e requerendo que o indivíduo seja capaz de agir de acordo com as deliberações feitas. ${ }^{7}$

Através das falas a seguir observa-se que, há expectativa por parte dos usuários em relação ao governo no que se refere à divulgação de informações e a utilização dos veículos de comunicação para isso: [...] se os órgãos responsáveis estão dando esse direito a população ele também deveria divulgar melhor. Porque senão só quem sabe, que é orientado usufrui desse direito, se é que tem! [...] (E8). A esse respeito temos que os meios de comunicação são verdadeiros agentes da participação social e a imprensa seu esteio principal. Assim, destaca-se o importante papel, por exemplo, do rádio, no Brasil, que está presente em cerca de $90 \%$ dos domicílios. Portanto, trata-se de fornecer subsídios para que os profissionais de comunicação do país se sintam capazes de discutir questões relativas às políticas públicas instituídas, com o intuito final de democratizar a informação em saúde e desenvolver o exercício da cidadania. ${ }^{13}$

Faz-se indispensável salientar que somente a informação sobre os direitos não resulta no seu pleno exercício pelos usuários com diabetes, sendo necessário que exista provisão de recursos por parte do Estado, bem como a sua adequada alocação e otimização, para que a utilização dos benefícios seja alcançada de forma justa e equitativa. ${ }^{14}$

Conforme os artigos $6^{\circ}$ e $7^{\circ}$ da Lei Orgânica de Saúde n0.080, de 19 de setembro de 1990, a assistência terapêutica e farmacêutica deve ser assegurada integralmente aos cidadãos brasileiros, de acordo com o princípio da integralidade do SUS. ${ }^{15}$ Ademais, a Lei 11.347/06 garante a assistência terapêutica e farmacêutica aos usuários com DM, incluindo medicamentos e insumos necessários ao tratamento dos usuários. ${ }^{3}$

Diante da falta de medicamentos, os usuários com DM recorrem a alternativas que implicam em custos adicionais. Dos doze participantes, nove afirmaram receber medicamento das unidades de saúde, quando há disponibilidade na rede. A fala a seguir evidencia dificuldades enfrentadas pelos participantes quando ocorre a falta de medicamentos ou insumos: [...] eu vou no posto e não é toda hora que tem remédio, então eu preciso comprar, né? [...] (E7). Além disso, quando não há na unidade referência de saúde do usuário o medicamento que ele necessita, e o mesmo não possui condições econômicas para comprar o medicamento, ele se desloca de uma unidade de saúde à outra, para verificar se há disponibilidade do determinado medicamento na outra unidade. Isso demonstra outra dificuldade apresentada pelos entrevistados diante da falta de medicamentos, como vemos na fala que se segue: [...] quando não tem o remédio no meu posto, eu sou obrigado a ir ao outro posto, quando chega lá, às vezes eles [profissionais de saúde] falam, nós temos esse (medicamento), mas não temos o outro. Então é uma dificuldade. [...] (E4).

Importante ressaltar que, dentre as medidas a serem tomadas com o objetivo de promover a melhoria da atenção à saúde com ampliação do acesso da população aos medicamentos fornecidos pelo SUS, em especial aos medicamentos utilizados para o controle da hipertensão arterial e DM, tem seu respaldo no "Programa mais saúde: direito de todos" ${ }^{16}$ Tal programa tem como finalidade aproveitar as potencialidades oferecidas pelo setor saúde como um dos elos vitais para um novo padrão de desenvolvimento brasileiro. O programa contempla 73 medidas e 165 metas com custo total previsto de $\mathrm{R} \$ 89,4$ bilhões de reais. Esse conjunto de iniciativas permite consolidar a percepção estratégica de que a saúde constitui uma frente de expansão que vincula o desenvolvimento econômico ao social. ${ }^{16}$

Nesse contexto, se por um lado cabe à administração pública organizar os serviços, visando atender, de forma integral e universal, o direito à assistência farmacêutica e terapêutica dos usuários, ${ }_{1}^{14}$ por outro, cabe aos profissionais de saúde fornecerem as informações necessárias para que esse atendimento seja eficaz e resulte no pleno exercício do direito dos usuários.

\section{As competências e responsabilidades dos profissionais de saúde: dever ético-moral em informar sobre direitos e permitir que esses sejam cumpridos}

O conhecimento dos direitos dos usuários é essencial para o desenvolvimento de uma cons- 
ciência democrática, responsável e reflexiva do cidadão, tanto no papel de usuário quanto no de profissional da saúde. Portanto, conhecer os direitos é o primeiro passo para diminuir as barreiras enfrentadas pelos usuários com DM para o acesso pleno a seus direitos de cidadania ${ }^{6}:[. .$.$] eles [os$ profissionais de saúde], sabendo de tudo, tinha que orientar os pacientes, que isso é uma falha grande de não orientar o paciente. Porque o paciente vai lá para ser orientado e ele [o profissional de saúde] não dá orientação, como é que fica? [...] (E10).

Para que as ações de saúde tenham o sentido transformador que o modelo de saúde vigente requer, elas precisam estar respaldadas no fato de que as informações sobre os direitos legais de cidadãos devem ser fornecidas por uma equipe multiprofissional de saúde capacitada e competente para tanto. Para isso, um dos eixos que o "Programa mais saúde: direito de todos" aponta como indispensável para a evolução do SUS, diz respeito à força de trabalho em saúde, que tem como diretriz a ampliação e a qualificação do trabalho em saúde. ${ }^{16}$

No entanto, apesar de todos os esforços para que haja capacitação profissional, a fala a seguir pode ser representativa de que os usuários parecem sentir falta de orientações básicas, como, por exemplo, aprender a administrar insulina no tecido subcutâneo. [...] acho que [os profissionais de saúde] deveriam informar melhor os pacientes. Dizer das políticas de saúde. Dizer dos direitos. Mas se eles não falam nem como aplica uma injeção, você acha que eles vão falar outra coisa! [...] (E9).

O Código de Ética em Enfermagem, em seu Art. 41, afirma que é responsabilidade e dever do profissional de enfermagem, prestar informações completas e fidedignas necessárias para assegurar a continuidade da assistência. Assim sendo, é função do profissional de Enfermagem prover informações aos usuários do sistema de saúde. ${ }^{17}$ Nesse sentido, espera-se que o profissional de enfermagem esteja capacitado para prestar informações aos usuários de saúde como um todo e, aos usuários com DM em específico.

Isso nos atenta para a necessidade de repensar o quanto o profissional de saúde tem refletido sobre a sua falta de compromisso para com os usuários do SUS, sobretudo, o quanto os profissionais, ainda carecem de perceber o seu papel de ator no modelo de saúde atual, ao agir de modo divergente do proposto pelo sistema. ${ }^{18}$

Um estudo foi realizado com 73 enfermeiras, em dois hospitais brasileiros, com objetivo de conhecer a percepção do enfermeiro acerca de sua atuação ante os direitos dos clientes. Os resultados apontaram que os direitos dos clientes mais respeitados pelas enfermeiras foram à preservação da individualidade do cliente, seguidos pelos direitos relativos ao respeito da autonomia, à identificação pessoal e, por último, o respeito ao direito referentes à informação para a tomada de decisão. ${ }^{19}$

Nesse sentido, "ignorar as necessidades de informação de um paciente é uma forma de crueldade" 20:63 e contraria o principio bioético da não-maleficência. Esse princípio consiste na obrigação de não causar prejuízos ou danos às pessoas. ${ }^{8}$ Assim, negar a informação aos usuários sobre seus direitos contraria, sobretudo, tal princípio.

Entretanto, conforme fala abaixo, os participantes vêem os profissionais de saúde como detentores do saber, e há confiança nesta relação. Os profissionais podem parecer, nas falas dos participantes, despreparados quanto ao fornecimento de orientações adequadas e corretas. [...] $a$ gente pensa que pode confiar neles [profissionais de saúde], mas de repente quando a gente fica sabendo que eles sabem de alguma coisa e não disseram nada a gente, essa confiança cai por água abaixo [...] (E6).

Além de toda a responsabilidade do profissional de enfermagem, prevista no Código de Ética, quanto à informação aos usuários, lhe é atribuído especificamente no Art. 23: a responsabilidade de "encaminhar a pessoa, família e coletividade aos serviços de defesa do cidadão" ${ }^{17: 52}$ Essa fala pode ser conotativa de que os devidos encaminhamentos às pessoas aos serviços de defesa do cidadão não têm sido efetuado na prática: [...] tinha que ter assim um lugar para as pessoas reclamarem, né? Porque não tem. Pelo menos eu não sei se tem algum lugar que a gente possa tá reclamando. Eu acredito que muitas pessoas acabam até ficando sem tomar o remédio porque não tem o dinheiro pra comprar e não sabe onde reclamar. Muita gente não tem o conhecimento de onde reclamar as coisas, como eu não tenho! [...] (E10). Diante dessa fala, percebe-se que o compromisso ético-profissional da equipe de enfermagem, não têm sido exercido em consonância com o que consta no Art. 23 do Código de Ética que rege a profissão.

Face à insatisfação, os participantes têm direitos a reclamar, fato que pouco se evidencia na prática clínica, uma vez que elas desconhecem a quem recorrer para registrar suas reclamações. Nessa direção, ainda, não se tem nos serviços de saúde os chamados "advogados do usuário", pois, "não há um grupo profissional com o monopólio ou a exclusividade da advocacia do doente e de que 
todos os profissionais têm o dever de cuidar dos que se entregam aos seus cuidados e confiam neles". 21:211

Em relação aos papéis dos profissionais da saúde sobre informação e orientação foi possível observar que, nas falas dos participantes, parece haver descaso na forma como a informação é oferecida. Quando há falta de medicamentos ou insumos os profissionais de saúde demonstram falta de cordialidade e de paciência aos usuários. A fala a seguir é esclarecedora nesse sentido: [...] eles [profissionais das unidades de saúde] tratam os pacientes assim:é sim, não, e "vai procurar em outro lugar", é "olha, aqui não tem". Eles não explicam as coisas direito, com paciência [...] (E9).

Diante do exposto, fica evidente que é preciso avançar quanto ao papel da equipe de saúde no oferecimento de informações e orientações aos usuários sobre sua doença, bem como os seus direitos como cidadão, com o intuito de alcançar, verdadeiramente, a humanização em saúde. Os serviços de saúde no Brasil precisam ir além de prevenir, curar e reabilitar: devem contribuir para o aumento da capacidade reflexiva dos usuários tornando-os sujeito social, conscientes de seus direitos e do "direito a ter direitos". 22:1094

\section{A participação dos usuários e a isenção de responsabilidade dos mesmos na busca por informações e formas de exercer seus direitos}

Para alguns dos participantes do estudo, o atendimento nos serviços de saúde consiste na busca de informações, fato esse que, proporcionaria a ampliação dos conhecimentos sobre os aspectos relacionados à saúde como um direito e resultaria na efetivação da saúde como direito de todos, ${ }^{23}$ conforme a fala: [...] eles [usuários dos serviços de saúde] têm que se informar mais, melhor, perguntar as coisas para as pessoas que sabem [...] (E3).

Assim, temos a responsabilidade dos usuários na aquisição de conhecimentos e na busca por informações relativas à sua saúde e aos seus direitos. Para o entrevistado a seguir, existe uma "falta de interesse" na busca de informações, por parte dos usuários da saúde: [...] falta de interesse. Porque não está precisando, porque quando você está precisando você vai atrás dos seus interesses. Você pode perguntar pra um ex-presidiário, ele sabe tudo da lei, do crime que ele cometeu. Ele sabe tudinho de cor e salteado. E também porque tem muita gente que é acomodada [...] (E9). Por outro lado, a fala a seguir expõe uma conduta exigente do usuário de saúde que é consciente de seus direitos e, portanto de capacidade de agir: [...] eu já peço e falo: "eu tenho direito a isso e eu quero, porque é um direito meu", se não fosse, ficava quieto [...] (E4).

No entanto, como já mencionado anteriormente, a capacidade de gozo de direitos nem sempre resulta na capacidade de agir para exercer direitos. ${ }^{24}$ Assim, as pessoas nem sempre estão empoderadas para exercerem seus direitos e nem sempre conseguem "erguer sua voz para sugerir modificações ou reclamar". 22:211 A esse exemplo, temos a fala: [...]olha, pra ser bem sincera eu não sei como lutar. Eu não sei como fazer isso, você entendeu? Eu não sei como porque já diz o ditado: 'a corda arrebenta pelo lado do mais fraco'. Então é difícil [...] (E7).

Importante salientar que a fala anterior denota uma relação de dependência e a percepção de impotência do participante frente às adversidades impostas pelas conformações do sistema de saúde. Além disso, confere aos usuários um perfil de categoria social destituída de poder que não consegue se organizar e vocalizar as suas demandas. ${ }^{25}$

Aqui se faz necessário dizer que, por meio do Decreto 4.726, 09 de junho de 2003, foi criada a Ouvidoria Geral doSUS, a qual tem por finalidade servir como um canal de articulação entre o usuário de saúde e a gestão pública de saúde e também assegurar aos cidadãos o acesso às informações sobre o direito à saúde e informações sobre como exercer esse direito. Dentre suas atribuições, temos o recebimento de solicitações, denúncias, reclamações, elogios e sugestões. ${ }^{13,26}$ Em contrapartida, os entrevistados parecem desconhecer a existência da Ouvidoria acima descrita e, consequentemente, não a compreendem como um instrumento legal para efetivar uma ação do controle social.

É possível notar que o participante revela que, além do constitucionalmente determinado, são necessárias outras atribuições para que os usuários usufruam de seus direitos. Dentre tais atribuições temos o conhecimento sobre como buscar o efetivo exercício dos direitos. A fala a seguir mostra que a uniformização de sujeitos está intrinsecamente relacionada ao quanto se conhece e conseqüentemente ao quanto se tem de capacidade para dialogar: [...] perante a lei, todo mundo é cidadão, mas na realidade as coisas não funcionam dessa forma. Se você precisa de uma determinada coisa, se você não tiver um determinado estudo, conhecimento, você não consegue. Isso a lei, a constituição diz que os direitos são iguais para todos, mas não éo que você vê na verdade. Porque as pessoas que têm mais conhecimento, sabem melhor fazer valer os seus direitos. Até para saber dialogar é diferente [...] (E4). 
Importante ressaltar que a justiça, aqui entendida enquanto princípio bioético, está estritamente interligada à equidade. Assim, a justiça estabelece padrões de distribuição de bens e a equidade é um desses padrões. Ao entender o conhecimento como um bem indispensável à legitimação dos direitos, de acordo com a fala acima, pode-se inferir que esse bem talvez não esteja sendo distribuído de maneira equânime e, portanto justa nos serviços de saúde para os usuários com DM. ${ }^{20}$

Se por um lado, ainda há incapacidade de alguns usuários em exercerem seus direitos, por outro alguns usuários dispõem de mecanismos informais que de alguma forma resultam no exercício do direito, embora muitas vezes eles tenham que abrir mão da cordialidade e reclamar para que sejam reconhecidos como pessoa autônoma e portadora de direitos. A fala a seguir é ilustrativa nesse sentido: [...] um dia eu falei lá para moça, "você quer ser bem atendida? Chuta o balcão aqui, cospe na cara da menina, apesar dela não ter nada a ver com isso, mas pelo menos vai chamar a atenção, aí vão arrumar remédio para você" [...] (E2).

$\mathrm{Na}$ tentativa de fazer prevalecer os seus direitos, alguns usuários buscam soluções que envolvem autoridades municipais, devido à facilidade de acesso a essas pessoas que são diretamente responsáveis pelas ações em saúde do município: [...] fazer uma reclamação para quem é de direito, por exemplo, numa cidade pequena como a que eu moro, vai falar lá no gabinete do prefeito, lá com a parte social, assistente social, tem que meter a boca, né? Eu acho assim, seé direito do cidadão, então vai reclamar [...] (E4).

Por fim, se o que se almeja é uma participação consciente e autônoma dos participantes na tomada de decisões e na efetivação dos seus direitos em DM. Para tanto, ainda há necessidade de ampla rede de informação tendo como ponto de partida o esclarecimento dos direitos dos usuários do sistema de saúde e funcionamento do SUS, a fim de alcançar a cidadania em saúde.

Uma possibilidade tem sido discutida na literatura são as atividades em grupo multiprofissional, onde as ações desenvolvidas e o envolvimento dos profissionais na construção de uma assistência de melhor qualidade demonstraram o potencial desta experiência na mudança da prática hegemônica em saúde em nossa sociedade. ${ }^{27}$ Outro ponto refere-se a inserção do componente ético como um norteador do ensino e do próprio cuidado em enfermagem, necessitando de ampliação dos estudos da ética e dos deveres pelos pesquisadores, professores e enfermeiros. ${ }^{28}$

\section{CONSIDERAÇÕES FINAIS}

A existência de leis não configura a sua praticidade e execução no âmbito da saúde. As leis são importantes no sentido de balizarem a consciência humana. No entanto, é preciso proteger os direitos e criar condições para que eles sejam exercidos. Tendo em vista que, a informação é indispensável para o processo de construção da cidadania, emergiu o tema a co-responsabilidade em saúde no que diz respeito ao fornecimento de informações e à efetivação dos direitos dos usuários com DM.

Em relação ao poder público, os participantes demonstram expectativa no que se refere à responsabilidade deste na divulgação de informações em saúde. Apontam que a utilização dos veículos de comunicação (rádio, televisão e jornais) como estratégia para a propagação dos direitos dos usuários com DM. No que se refere às responsabilidades dos profissionais da saúde sobre informação e orientação, as falas dos participantes mostram que há dificuldades quanto à forma como a informação é oferecida, principalmente, quando há falta de medicamentos ou insumos. Por outro lado, a responsabilidade dos usuários na busca por informações relativas à sua saúde e seus direitos ainda reflete a falta de interesse e o desconhecimento do exercício de reivindicar os seus direitos em situações adversas.

Para tanto, é necessário que os profissionais de saúde conheçam os benefícios advindos das legislações, que vão além de distribuir gratuitamente os insumos e os medicamentos, de forma regular e equitativa para todos os usuários com DM. Há necessidade de prover todas as informações necessárias para que o usuário com DM tome a decisão em relação ao seu tratamento de maneira autônoma, bem como a importância da capacitação dos profissionais para educar, orientar e respeitar a capacidade de autonomia dos usuários.

Acredita-se que dificilmente o usuário de saúde seja capaz de reivindicar e ou lutar pelos seus direitos, sem a necessária e suficiente informação para exercer a sua autonomia. Promover a qualidade da assistência em saúde, por meio do respeito aos direitos dos usuários e, principalmente, por meio de ações informativas, beneficentes e justas que resultem na intensificação do exercício da autonomia dos usuários com DM, deve ser, portanto, a meta a ser atingida pelos profissionais de saúde.

Ao considerar que a enfermagem representa o elo entre os usuários e as instituições de saúde, o fornecimento de informação adequada aos 
usuários de saúde nos remete à função social da enfermagem. Dessa forma, espera-se que os resultados aqui apresentados sobre o conhecimento dos usuários com DM acerca dos seus direitos e benefícios advindos da legislação vigente possam contribuir para a assistência de enfermagem qualificada, responsável e coerente com os princípios bioéticos da beneficência, não-maleficência, justiça e respeito à autonomia aos usuários com DM. Espera-se também, contribuir para a atuação multiprofissional em diabetes no que tange ao fornecimento de informações em saúde.

\section{REFERENNCIAS}

1. Sociedade Brasileira de Diabetes. Tratamento e acompanhamento do diabetes mellitus. Rio de Janeiro (RJ): SBD; 2007.

2. Organização Mundial de Saúde (OMS). Cuidados inovadores para condições crônicas: componentes estruturais de ação: relatório mundial. Brasília (DF): OMS; 2003.

3. Brasil. Lei ${ }^{\circ} 11.347$ de 27 de setembro de 2006: dispõe sobre a distribuição gratuita de medicamentos e materiais necessários à sua aplicação e à monitoração da glicemia capilar aos portadores de diabetes inscritos em programas de educação para diabéticos. Diário Oficial da República Federativa do Brasil, 28 Set 2006.

4. Brasil. Portaria $n^{\circ} 2583$ de 10 de outubro de 2007: define elenco de medicamentos e insumos disponibilizados pelo SUS nos termos da Lei n¹1347, de 2006, aos usuários portadores de diabetes mellitus. Diário Oficial da República Federativa do Brasil, 15 Out 2007.

5. Pessini L, Barchifontaine CP. Problemas atuais de bioética. 6a ed. São Paulo (SP): Loyola; 2002.

6. Gauderer EC. Os direitos do paciente. $7^{\mathrm{a}} \mathrm{ed}$. Rio de Janeiro (RJ): Record; 1998.

7. Beauchamp TL, Childress JF. Princípios de ética biomédica. $4^{\mathrm{a}}$ ed. São Paulo (SP): Edições Loyola; 2002.

8. Garrafa V, Oselka G, Diniz D. Saúde pública, bioética e equidade. Bioética. 1997; 5(1):27-33.

9. Mascarenhas NB, Rosa DOS. Bioética e formação do enfermeiro: uma interface necessária. Texto Contexto Enferm. 2010 Abr-Mai; 19(2):366-371.

10. Minayo MCS. O desafio do conhecimento: pesquisa qualitativa em saúde. $4^{\text {a }}$ ed. São Paulo (SP): HUCITEC, 1996.

11. Gentilli V. Democracia de massas: jornalismo e cidadania. Estudo sobre as sociedades contemporâneas e o direito dos cidadãos à informação. Porto Alegre (RS): EDIPUCRS; 2005.

12. Selli L, Vial EA. Justiça como autonomia dos indivíduos. Rev Bras Bioética. 2006; 2(3):328-340.

13. Ministério da Saúde (BR). Direitos dos usuários dos serviços e das ações de saúde no Brasil: legislação compilada - 1973 a 2006. Brasília (DF): Ministério da Saúde; 2007.

14. Marques SB, Dallari SG. Garantia do direito social à assistência farmacêutica no Estado de São Paulo. Rev Saúde Pública. 2007 Fev; 41(1):101-7.

15. Brasil. Lei n ${ }^{\circ} 8.080$, de 19 de setembro de 1990: dispõe sobre as condições para promoção e recuperação da saúde, a organização e o funcionamento dos serviços correspondentes e dá outras providências. Diário Oficial da República Federativa do Brasil, 20 Set 1990.

16. Ministério da Saúde (BR). Mais saúde: direito de todos: 2008-2011. Brasília (DF): Editora do Ministério da Saúde; 2008.

17. Conselho Regional de Enfermagem de São Paulo. Principais legislações para o exercício da enfermagem. São Paulo(SP): COREN-SP; 2011;

18. Erdmann AL, Baches DE, Kloch P, Koerich MS, Rodrigues ACRL, Drago LC. Discutindo o significado de cidadania a partir dos direitos dos usuários da Saúde. Rev Enferm UERJ. 2008 Out-Dez; 16(4):477-81.

19. Alves PC, Lunardi VL, Lunardi GL, Lunardi Filho WD. A percepção das enfermeiras acerca da sua atuação ante os direitos dos clientes. Rev Esc Enferm USP. 2008 Jun; 42(2):242-8.

20. Drane J, Pessini L. Bioética, medicina e tecnologia desafios éticos na fronteira do conhecimento humano. São Paulo (SP): Edições Loyola. 2005.

21. Nunes L. Usuários dos serviços de saúde e os seus direitos. Rev Bras Bioética. 2006; 2(2):201-19.

22. Carvalho SR. Os múltiplos sentidos da categoria "empowerment" no projeto de promoção à saúde. Cad Saúde Pública. 2004 Jul-Ago; 23(8):1088-95.

23. Vásquez ML, Silva MRF, Campos ES, Arruda IKG, Diniz AS, Veras IL et al. Participação social nos serviços de saúde: concepções dos usuários e líderes comunitários em dois municípios do Nordeste do Brasil. Cad Saúde Pública. 2003 Mar-Abr: 19(2):57991.

24. Marchi MM, Sztajn R. Autonomia e heteronomia na relação entre profissional de saúde e usuário dos serviços de saúde. Rev Bioética.1998; 6(1):39-45.

25. Vaistman J, Andrade GRB. Satisfação e responsividade: formas de medir a qualidade e a humanização da assistência à saúde. Ciênc Saúde Coletiva. 2005 Jul-Set; 10(3):599-613.

26. Brasil. Decreto $n^{\circ} 4.726$, de 09 de junho de 2003 : aprova a Estrutura Regimental e o Quadro Demonstrativo dos Cargos em Comissão e das Funções Gratificadas do Ministério da Saúde, e dá outras providências. Diário Oficial da República Federativa do Brasil, 17 Jun 2003. 
27. Tavares CMA, Matos E, Gonçalves L. Grupo multiprofissional de atendimento ao diabético: uma perspectiva de atenção interdisciplinar à saúde. Texto Contexto Enferm [online]. 2005 Jun [acesso 2011 Mar 25]; 14(2):213-21. Disponível em: http:/ / www.scielo.br/scielo.php?script=sci_arttext\&pid= S010407072005000200008\&lng $=p t$

28. Carneiro AD, Costa SFG, Pequeno MJP. Disseminação de valores éticos no ensino do cuidar em enfermagem: estudo fenomenológico. Texto Contexto Enferm. 2009 Out-Dez; 18(4):722-30. 